\title{
Two Doses of Early Intravenous Dexamethasone for the Prevention of Bronchopulmonary Dysplasia in Babies with Respiratory Distress Syndrome ${ }^{1}$
}

\author{
RAYMOND J. SANDERS, ${ }^{2}$ CHRISTOPHER COX, DALE L. PHELPS, AND \\ ROBERT A. SINKIN
}

Departments of Pediatrics (Neonatology) [R.J.S., D.L.P., R.A.S.J and Biostatistics /C.C.], Strong Children's Medical Center, Rochester, New York 14642

\section{ABSTRACT}

Bronchopulmonary dysplasia is an important complication of ventilation in babies for which treatment with steroids has been advocated. We report the results of a phase I study of early i.v. dexamethasone to prevent the development of bronchopulmonary dysplasia in a high-risk population of ventilated premature babies, $<30 \mathrm{wk}$ gestation, with surfactant-treated respiratory distress syndrome. This study used a limited dexamethasone dosing regimen to minimize toxicity but used administration early in the course of acute lung disease to interrupt the injury cycle. Forty babies were enrolled; 19 were randomized to receive dexamethasone $(0.5 \mathrm{mg} / \mathrm{kg}$ birth weight at $12-18 \mathrm{~h}$ of age and a second dose $12 \mathrm{~h}$ later) and 21 were randomized to receive placebo (i.v. saline). The dexamethasone group required less ventilatory support (mean airway, peak inspiratory and end expiratory pressures, and intermittent mandatory ventilation) and supplemental oxygen after study d 4 (all $p<0.05$, repeated measures analysis of variance). Improved tidal volume in the dexamethasone group, as measured by pulmonary function testing of infants who remained intubated, was seen on study $\mathrm{d} 7(p=$ $0.02, t$ test). The dexamethasone group required shorter hospitalizations (median of $95 \mathrm{~d}$ versus $106 \mathrm{~d}, p=0.01$ ) (proportional hazards regression). Survival in the dexa- methasone group was $89 \%$ versus $67 \%$ in the placebo group ( $p=0.08, \chi^{2}$ analysis). Survival without bronchopulmonary dysplasia, diagnosed at $36 \mathrm{wk}$ corrected gestational age, was $68 \%$ in the dexamethasone group versus $43 \%$ in the placebo group $(p=0.14)$. Mean blood pressure was elevated on study d 4 through 7 in the dexamethasone group, but this difference resolved by study d 10 without pharmacologic intervention. No differences in hyperglycemia, incidence of intraventricular hemorrhage (or its severity), or days to regain birth weight were seen. Early administration of dexamethasone resulted in short-term and suggested long-term benefits without significant complications. The results of this trial justify a large scale, broaderbased (phase II) trial in premature babies with respiratory distress syndrome to determine the limits of effectiveness and the incidence of less-frequent potential side effects. (Pediatr Res 36: 122-128, 1994)

$\quad$ Abbreviations
BPD, bronchopulmonary dysplasia
FiO $_{2}$, fraction of inspired oxygen concentration
MAP, mean airway pressure
RDS, respiratory distress syndrome
CGA, corrected gestational age

requiring home medical care and frequent outpatient visits (1-5). The incidence of BPD has an inverse relationship with birth weight and gestational age (6). With the development and application of exogenous surfactant replacement therapy for the treatment of RDS as well as other advances in neonatal care, survival of low birth weight, extremely premature babies is increasing. The greatest risk for the development of BPD accompanies the improved survival in this group of babies.

Steroids have been used in a number of controlled trials to treat established BPD and have demonstrated significant short-term improvements in lung function (79). Postulated mechanisms by which steroids might improve lung function include the stabilization of cell and 
lysosomal membranes, increase in surfactant synthesis, inhibition of prostaglandin and leukotriene synthesis, decrease in neutrophil recruitment to the lung, enhancement of $\beta$-adrenergic activity, and reduction of pulmonary edema (10). A controlled trial of steroids in ventilated premature babies, administered at $2 \mathrm{wk}$ of age, resulted in improved pulmonary and neurodevelopmental outcomes (11). Although these babies were treated early, before developing BPD by classic definitions (i.e. $28 \mathrm{~d}$ of age with an oxygen requirement and characteristic chest $x$-ray changes), this study did not address prophylactic steroids to prevent the development of BPD. Evidence suggests that the pathophysiology of BPD may begin shortly after birth in susceptible babies (12). One controlled trial has investigated the use of prophylactic steroids in babies with RDS before the development of BPD (13). In that study, early ( $<12$ h) i.v. dexamethasone was given to premature babies with RDS, and the course was tapered over a 12-d period (13). Infants were a mean of 30 wk gestation and surfactant was not used. The results showed improved pulmonary function, earlier extubation, and a decreased incidence of lung injury in the treatment group; however, this group also demonstrated increased blood pressure, increased plasma glucose concentrations, and delayed somatic growth (13). This raised concerns over the safety of using steroids in a very-lowbirth-weight population.

The potential for serious sequelae from the use of steroids in premature babies remains a concern. At the same time, we also wished to learn whether a benefit could accrue to younger, surfactant-treated infants. Therefore, we conducted a study to estimate the efficacy and safety of a short course of dexamethasone to ventilator-dependent premature babies with surfactant-treated RDS. We limited the duration of dexamethasone administration to two doses to reduce the potential risk for significant sequelae and to test our hypothesis that the onset of BPD is based on an early inflammatory lung injury.

\section{METHODS}

This study was performed at the University of Rochester Medical and Strong Children's Research Centers, Rochester, New York, from December 1989 through January 1991 . The study was approved by the Research Subjects Review Board of the University and informed consent was obtained from the babies' parents.

Patient population. Babies of less than 30 wk gestation were eligible if they had RDS diagnosed by clinical and radiographic signs, required mechanical ventilation at 12-18 $\mathrm{h}$ of age, and had received at least one dose of exogenous surfactant. During the enrollment period of the study, all babies born at the University of Rochester of less than $29 \mathrm{wk}$ gestation received the first dose of exogenous surfactant in the delivery room prophylactically based on our demonstration of its superiority over rescue therapy in this population (14). Babies of 29-30 wk gestation, inclusive, who were born outside of or at the University of Rochester received exogenous surfactant if they met specific criteria after admission. The purpose for requiring exogenous surfactant replacement therapy for study eligibility was to maintain as uniform a study population as possible. All infants were eligible to receive subsequent doses of exogenous surfactant if they continued to require mechanical ventilation with an MAP $\geq 7$ torr, an $\mathrm{FiO}_{2} \geq 0.4$, or both. Exclusion criteria at entry included a strong suspicion of sepsis or pneumonia (i.e. chest $\mathrm{x}$-ray findings not consistent with RDS, cardiovascular instability, neutropenia, severe maternal chorioamnionitis), congenital heart disease, chromosomal abnormalities, and those infants who received an exchange transfusion.

Randomization. After identification of eligible babies and informed consent, an order form was sent to the pharmacy. There babies were randomized to the dexamethasone or placebo group according to a set of sealed envelopes. A syringe labeled "dexamethasone study drug," containing either the appropriate dose of dexamethasone or normal saline placebo according to the randomization schedule, was then sent to the nursery. A second syringe identical with the first was sent to the nursery $12 \mathrm{~h}$ later.

Intervention. The treatment group received one dose of i.v. dexamethasone $(0.5 \mathrm{mg} / \mathrm{kg}$ birth weight $)$ between 12 and $18 \mathrm{~h}$ of age and a second dose $12 \mathrm{~h}$ later. The placebo group received an equal volume of i.v. normal saline using the same dosing schedule. Investigators and caretakers were blinded to the study drug. All other aspects of care were according to the standard practice of the neonatal intensive care unit at the Strong Children's Medical Center.

Short-term clinical outcome variables and pulmonary function testing. Short-term clinical outcome variables were obtained on $\mathrm{d} 1$ through 7 and $\mathrm{d} 10$ of age and included weight, mean blood pressure, peak blood glucose, complete blood counts with differential, need for insulin or antihypertensive therapies, need for pharmacologic blood pressure support, and degree of ventilatory support. The latter included results of blood gas analysis (pH and blood gas tension values) and ventilator settings: peak inspiratory pressure, peak end-expiratory pressure, MAP, intermittent mandatory ventilation, and $\mathrm{FiO}_{2}$. Pulmonary function testing was scheduled for $\mathrm{d} 7$ for those infants who remained ventilated, and determinations of minute ventilation, tidal volume, compliance, and resistance were made (15). During pulmonary function testing, infants were placed on endotracheal tube continuous positive airway pressure and only spontaneous breaths were analyzed.

Long-term clinical outcome variables. Long-term clinical outcome variables included survival, disposition (i.e. discharged to home, transferred to another hospital, died), age at extubation, days on the ventilator, days requiring supplemental oxygen, days to regain birth weight, presence and severity of intraventricular hemorrhage, need 
for home oxygen and medications (i.e. diuretics, bronchodilators, methylxanthines), total number of hospital days (this includes hospital days at other institutions for infants transferred before discharge home), and survival without BPD. BPD was defined as the need for supplemental oxygen and characteristic chest $x$-ray changes at 36 wk CGA (16). All x-rays were read in a blinded fashion by a single pediatric radiologist.

Statistical analysis. Continuous variables were analyzed using $t$ tests and analysis of covariance with adjustment for birth weight. Measurements recorded at a number of different time points were analyzed by repeated measures analysis of variance with the Greenhouse-Geisser correction for degrees of freedom. Discrete variables were analyzed using Mann-Whitney tests and $\chi^{2}$ tests. Survival type endpoints, such as days in the hospital, were analyzed using the Kaplan-Meier estimate of the survival function. Proportional hazards regression analysis was used to adjust for birth weight. For endpoints such as days in the hospital, babies who died were treated as never discharged, i.e. infants who died were assigned a value equal to the longest observation time in the study. Thus, when the Kaplan-Meier curves are computed, such infants remain in the risk set for the entire analysis. In practical terms, then, such babies are treated as not reaching endpoint (discharged or extubated) for the entire time interval under analysis. This was done to avoid biasing the survival analysis by having babies who died removed from the analysis. All $p$ values are two-sided.

\section{RESULTS}

Patient population. During the study period, 113 babies of less than $30 \mathrm{wk}$ gestation were admitted to the University of Rochester neonatal intensive care unit. Of these 113, 28 did not meet entry criteria, eight died before enrollment, 24 were excluded due to presumed sepsis, two were not enrolled because of refused parental consent, one was deemed too critically ill by the neonatal attending physician, and 10 missed enrollment. Forty babies were enrolled during the study period, with 21 randomized to the placebo group and 19 randomized to the dexamethasone group. No differences were seen between the two groups with respect to birth weight, estimated gestational age, gender, race, 1- and 5-min Apgar scores, initial white blood cell count, the number receiving prophylactic surfactant, or antepartum factors (Table 1).

Table 2 summarizes clinical and laboratory characteristics immediately before treatment intervention. No clinically significant differences were seen between the two groups with respect to degree of ventilatory support, blood gas results, serum glucose, or mean blood pressure.

Pulmonary function. The goal of the ventilatory strategy used was to maintain the arterial $\mathrm{PO}_{2}$ between 6.7 and 9.3 $\mathrm{kPa}\left(50\right.$ and $70 \mathrm{~mm} \mathrm{Hg}$ ) and the arterial $\mathrm{PCO}_{2}$ between 6.0 and $7.3 \mathrm{kPa}(45$ and $55 \mathrm{~mm} \mathrm{Hg}$ ). Figure 1 displays the MAP and $\mathrm{FiO}_{2}$ (panels $\mathrm{A}$ and $\mathrm{B}$, respectively) over time
Table 1. Antenatal and baseline characteristics*

\begin{tabular}{|c|c|c|}
\hline \multirow[b]{2}{*}{ Feature } & \multicolumn{2}{|c|}{ Group } \\
\hline & $\begin{array}{c}\text { Dex } \\
(n=19) \dagger\end{array}$ & $\begin{array}{l}\text { Placebo } \\
(n=21) \dagger\end{array}$ \\
\hline \multicolumn{3}{|l|}{ Infant } \\
\hline Birth weight (g) & $831 \pm 54.6$ & $839 \pm 49.1$ \\
\hline EGA (wk) & $26.2 \pm 0.44$ & $26.9 \pm 0.46$ \\
\hline Gender (\% male) & 47 & 48 \\
\hline Race (\% white) & 58 & 57 \\
\hline Apgar at $1 \mathrm{~min}$ & $3(1-7) \ddagger$ & $5(1-8) \ddagger$ \\
\hline Apgar at $5 \mathrm{~min}$ & $7(1-9) \ddagger$ & $8(2-9) \ddagger$ \\
\hline WBC $\left(\times 10^{3} / \mathrm{mL}\right)$ & $14.7 \pm 3.65$ & $11.7 \pm 1.96$ \\
\hline Prophylactic surfactant & $14(74 \%)$ & $16(76 \%)$ \\
\hline \multicolumn{3}{|l|}{ Antepartum } \\
\hline $\begin{array}{l}\text { Rupture of membranes } \\
\qquad(\%>18 \mathrm{~h})\end{array}$ & $29[17]$ & 18 [17] \\
\hline Maternal steroids (\%) & 32 & 43 \\
\hline Maternal WBC $\left(\times 10^{3} / \mathrm{mL}\right)$ & $16.4 \pm 1.2[15]$ & $14.5 \pm 0.8[20]$ \\
\hline $\begin{array}{l}\text { Positive maternal cervical } \\
\text { culture }(\%)\end{array}$ & $38[16]$ & $39[18]$ \\
\hline Chorioamnionitis (\%) & 39 & 29 \\
\hline
\end{tabular}

* Mean \pm SEM (unless otherwise noted). EGA, estimated gestational age. WBC, white blood cell count.

+ When data were unavailable, the reduced sample denominator is indicated in brackets.

$\ddagger$ Median (range).

Table 2. Pretreatment clinical and laboratory characteristics*

\begin{tabular}{|c|c|c|}
\hline \multirow[b]{2}{*}{ Variable } & \multicolumn{2}{|c|}{ Group } \\
\hline & $\operatorname{Dex}(n=19)$ & Placebo $(n=21)$ \\
\hline $\mathrm{FiO}_{2}$ & $0.31 \pm 0.02$ & $0.31 \pm 0.03$ \\
\hline $\operatorname{MAP}\left(\mathrm{cm} \mathrm{H} \mathrm{H}_{2} \mathrm{O}\right)$ & $5.96 \pm 0.44$ & $5.77 \pm 0.28$ \\
\hline IMV (breaths/min) & $26 \pm 2$ & $25 \pm 2$ \\
\hline $\mathrm{PIP}\left(\mathrm{cm} \mathrm{H} \mathrm{H}_{2} \mathrm{O}\right)$ & $16 \pm 1$ & $16 \pm 1$ \\
\hline PEEP $\left(\mathrm{cm} \mathrm{H}_{2} \mathrm{O}\right)$ & $3.8 \pm 0.2$ & $3.8 \pm 0.1$ \\
\hline $\mathrm{PaO}_{2}(\mathrm{kPa})$ [torr] & $8.7 \pm 0.5[65 \pm 4]$ & $8.9 \pm 0.5[67 \pm 4]$ \\
\hline $\mathrm{PaCO}_{2}(\mathrm{kPa})[$ torr $]$ & $4.4 \pm 0.8[33 \pm 6]$ & $4.5 \pm 0.3[34 \pm 2]$ \\
\hline $\begin{array}{l}\text { Blood glucose } \\
(\mathrm{mmol} / \mathrm{L})[\mathrm{mg} \%]\end{array}$ & $7.0 \pm 0.6[126 \pm 11]$ & $5.5 \pm 0.3[99 \pm 6]$ \\
\hline $\begin{array}{l}\text { Mean blood pressure } \\
(\mathrm{kPa}) \text { [torr] }\end{array}$ & $4.5 \pm 0.1[34 \pm 1]$ & $4.6 \pm 0.3[35 \pm 2]$ \\
\hline
\end{tabular}

* Mean \pm SEM. Dex, dexamethasone; IMV, intermittent mandatory ventilation; PIP, peak inspiratory pressure; PEEP, peak end-expiratory pressure; $\mathrm{PaO}_{2}$, arterial $\mathrm{Po}_{2} ; \mathrm{PaCO}_{2}$, arterial $\mathrm{PCO}_{2}$.

in the dexamethasone and placebo groups. These data were analyzed using two-way repeated measures analysis of variance. This analysis includes a test of interaction whose null hypothesis states that the two curves are parallel over time. A significant result indicates that the two curves are not parallel and therefore that differences between the two groups change over time (and in particular are not all zero). The nature of these differences can be seen in Figure 1. Infants in the dexamethasone group required less MAP after study d 3; $p=0.003$ for the test of interaction indicated a significant change in the difference between the two groups over time (Fig. $1 A$ ), with the largest differences occurring after $d 3$. Similar statistically significant findings were also seen for peak inspiratory pressure, peak end-expiratory pressure, and intermittent mandatory ventilation (data not shown). In addition to decreased ventilatory support, infants in the 

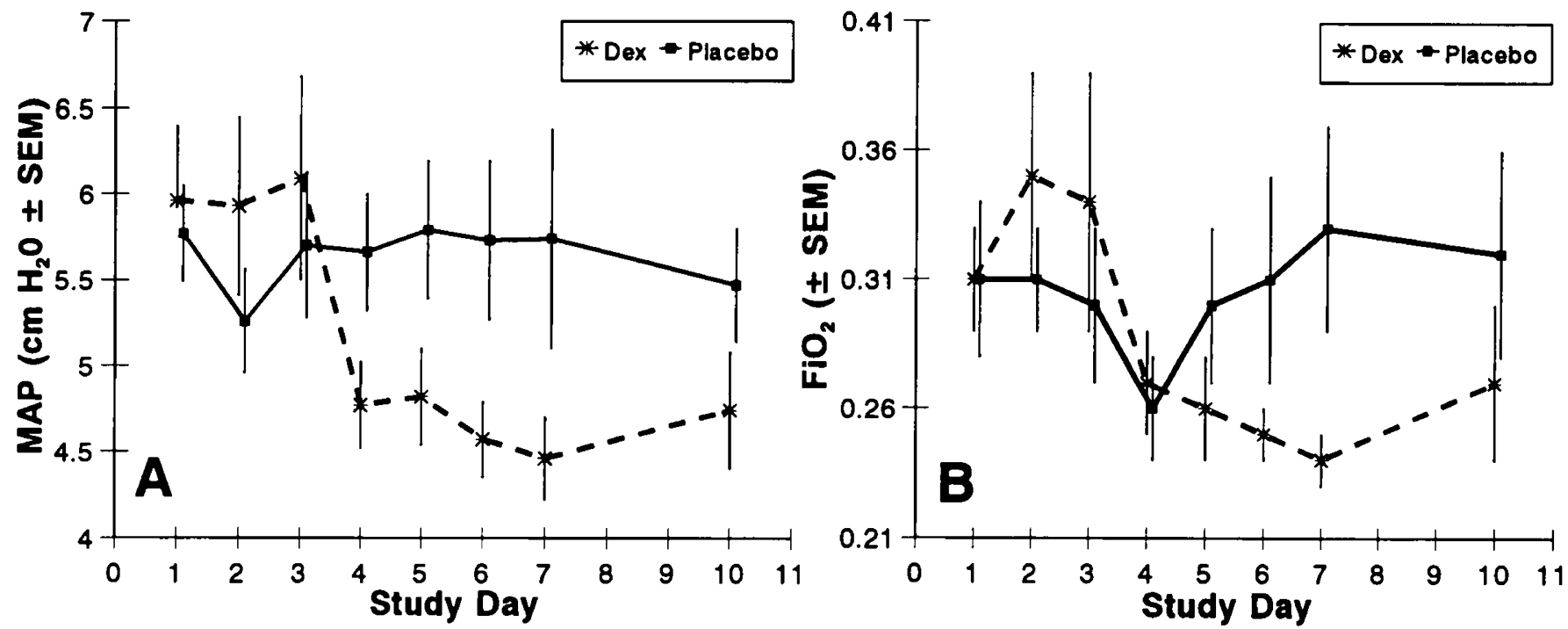

Figure 1. Changes in MAP $(A)$ and $\mathrm{FiO}_{2}(B)$ during the first $10 \mathrm{~d}$ of age (mean $\pm \mathrm{SEM}$ ) by study group.

dexamethasone group required less supplemental oxygen after study d 4, with the greatest differences on study d 6 and $7(p=0.04$, test of interaction) (Fig. $1 B)$. Blood gas analyses revealed no significant differences between the two groups during the same period (data not shown).

Pulmonary function testing, including measurements of tidal volume, minute ventilation, compliance, and resistance, was performed on study d 7. Tidal volumes were significantly higher in babies receiving dexamethasone $(p=0.02, t$ test) (Table 3 ). This examination was obviously limited by extubation of the healthier infants before pulmonary function testing could be performed. However, there was no significant difference between the two groups with respect to the percentage of infants extubated and alive at $\mathrm{d} 7$.
Long-term outcome. Survival in the dexamethasone group was 17 of $19(89 \%)$ versus 14 of $21(67 \%)$ in the placebo group ( $p=0.08, \chi^{2}$ analysis) (Table 3 ). Survival analysis using proportional hazards regression with adjustment for birth weight produced similar results. Table 4 lists the primary and secondary diagnoses and the age at death for the nonsurvivors from both groups. One infant in the dexamethasone group and one infant in the placebo group died during the first week postpartum. Infants in the dexamethasone group required fewer days of mechanical ventilation and fewer days in the hospital (Table 3). The Kaplan-Meier curves for percentage of patients extubated and discharged home versus age in days are shown in Figure 2. The cumulative rates of extubation seem to be very similar until about $40 \mathrm{~d}$, when the rate of

Table 3. Study outcomes*

\begin{tabular}{|c|c|c|c|}
\hline & \multicolumn{2}{|c|}{ Group } & \multirow[b]{2}{*}{$p$} \\
\hline & $\operatorname{Dex}(n=19)$ & Placebo $(n=21)$ & \\
\hline \multicolumn{4}{|l|}{ Early (first week) } \\
\hline Surfactant doses $(\%>1) \dagger$ & 37 & 33 & 0.92 \\
\hline Died $\dagger$ & $1(5.2 \%)$ & $1(4.8 \%)$ & 0.73 \\
\hline Extubated and alive at $d 7$ & $4(21 \%)$ & $7(33 \%)$ & 0.38 \\
\hline Pulmonary function test $(n)$ & 14 & 13 & \\
\hline Tidal volume $(\mathrm{mL} / \mathrm{kg})$ & $7.36 \pm 0.48$ & $5.92 \pm 0.37$ & 0.03 \\
\hline Minute ventilation $(\mathrm{mL} / \mathrm{kg} / \mathrm{min})$ & $379 \pm 22$ & $359 \pm 28$ & 0.58 \\
\hline Compliance $\left(\mathrm{mL} / \mathrm{cm} \mathrm{H}_{2} \mathrm{O}\right)$ & $1.46 \pm 0.15$ & $1.36 \pm 0.32$ & 0.80 \\
\hline Resistance $\left(\mathrm{cm} \mathrm{H}_{2} \mathrm{O} / \mathrm{L} / \mathrm{s}\right)$ & $56.5 \pm 8.8$ & $58.7 \pm 12.6$ & 0.89 \\
\hline \multicolumn{4}{|l|}{ Long-term outcome } \\
\hline Survival† & $17(89 \%)$ & $14(67 \%)$ & 0.08 \\
\hline Mechanical ventilation $(\mathrm{d}) \ddagger$ & 35 & 47 & 0.08 \\
\hline Supplemental oxygen (d) $\ddagger$ & 44 & 73 & 0.35 \\
\hline Hospitalization (d) $\ddagger$ & 95 & 106 & 0.01 \\
\hline Survival without BPD† & $13(68 \%)$ & $9(43 \%)$ & 0.14 \\
\hline Survival without BPD and without late steroids $\dagger$ & $12(63 \%)$ & $9(43 \%)$ & 0.16 \\
\hline Alive at 36 wk CGA with BPD and received late steroids $\dagger$ & $2(10 \%)$ & $3(14 \%) \S$ & 0.25 \\
\hline
\end{tabular}

* Mean \pm SEM; $t$ test (unless otherwise noted). Dex, dexamethasone.

$\dagger \chi^{2}$ analysis or Fischer's exact test, as appropriate.

¥ Median; proportional hazards regression (two-sided).

$\S$ Two of these infants died after 36 wk CGA. 
Table 4. Diagnoses of nonsurvivors (primary cause of death)*

\begin{tabular}{ccccc}
\hline $\begin{array}{c}\text { Patient } \\
\text { gender }\end{array}$ & Group & $\begin{array}{c}\text { Age at } \\
\text { death (d) }\end{array}$ & $\begin{array}{c}\text { Primary } \\
\text { diagnosis }\end{array}$ & Other diagnoses \\
\hline Boy & Placebo & 2 & Pneumothorax & $\begin{array}{c}\text { IVH, pulmonary } \\
\text { hemorrhage } \\
\end{array}$ \\
Girl & Placebo & 102 & CMV pneumonia & BPD \\
Boy & Placebo & 17 & NEC & \\
Boy & Placebo & 29 & NEC & BPD \\
Girl & Placebo & 9 & IVH & \\
Girl & Placebo & 155 & BPD & \\
Boy & Placebo & 94 & Renal failure & BPD \\
Girl & Dex & 19 & IVH & BPD \\
Girl & Dex & 3 & IVH & \\
\hline
\end{tabular}

* IVH, intraventricular hemorrhage; NEC, necrotizing enterocolitis; CMV, cytomegalovirus; Dex, dexamethasone.
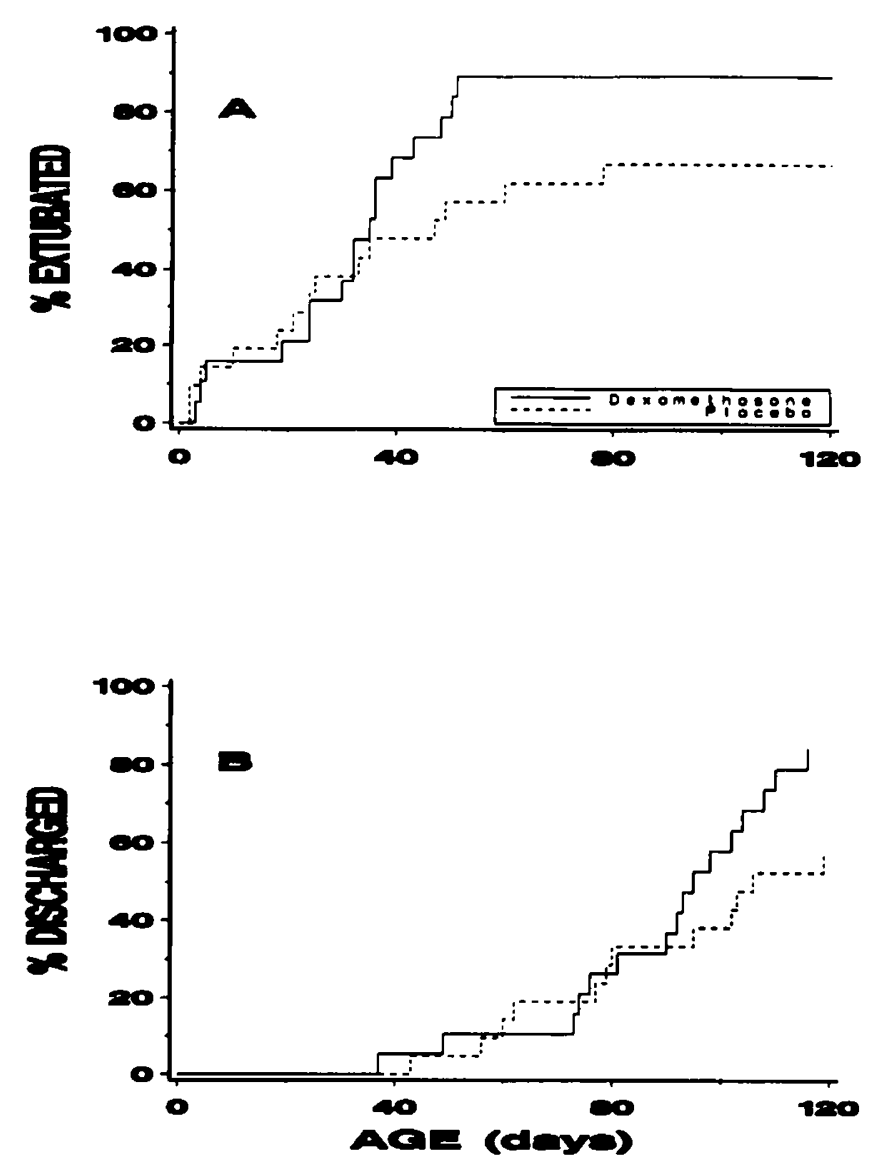

Figure 2. Kaplan-Meier curves for the percentage of babies extubated $(A)$ and the percentage of babies discharged $(B) v S$ age in days by study group.

extubation rises dramatically in the dexamethasonetreated group, exceeding $90 \%$ by $50 \mathrm{~d}$. In contrast, the cumulative rate for extubation in the placebo group does not exceed $70 \%$ by $120 \mathrm{~d}$. Similarly, the cumulative rates for the percentage of patients discharged in both groups are approximately equivalent until $90 \mathrm{~d}$, at which point the groups diverge. The cumulative rate in the dexamethasone group approaches $90 \%$, whereas in the placebo group it does not exceed $70 \%$ by $120 \mathrm{~d}$. Survival without BPD, diagnosed at 36 wk CGA, was $68 \%$ in the dexamethasone group compared with $43 \%$ in the placebo group ( $p=0.14, \chi^{2}$ analysis) (Table 3 ) (95\% confidence interval for difference between the treatment groups was $-4.2 \%$ to $55.3 \%$ ). One baby in the dexamethasone group who survived without BPD received late steroids (i.e. after $d 2$ of age). Survival without BPD and without late steroids was $63 \%$ (12 of 19$)$ in the dexamethasone group and $43 \%$ (nine of 21$)$ in the placebo group $\left(p=0.16, \chi^{2}\right.$ analysis) (Table 3) (95\% confidence interval for this difference was $-10.0 \%$ to $50.6 \%$ ). Among the four surviving infants in the dexamethasone group with BPD, two were treated with late steroids. In the 14 placebo survivors, nine were free of BPD at $36 \mathrm{wk}$ CGA, and none of these infants were treated with late steroids. Among the five surviving placebo infants with BPD, one was treated with late steroids. For the three placebo-treated infants who died after 36 wk CGA, all had BPD and two were treated with late steroids.

Complications. No significant differences between the two groups were seen with respect to the incidence or severity of intraventricular hemorrhage, the need for insulin therapy, the need for antihypertensive therapies, the number of positive admission blood cultures, or the number of days to regain birth weight (Table 5). No clinically significant differences were noted in the mean daily blood glucose values, although values were greater in the dexamethasone group (Fig. $3 A$ ). Mean blood pressure was elevated on study d 4 through 7 in the dexamethasone group (Fig. 3B). This difference, however, resolved by study $\mathrm{d} 10$ without pharmacologic intervention. No significant differences between the two groups were seen with respect to necrotizing enterocolitis, retinopathy of prematurity, air leak (i.e. pneumothorax or pulmonary interstitial emphysema), or the need for home oxygen or medications (Table 5).

\section{DISCUSSION}

The incidence of BPD is increasing because of the improved survival of critically ill premature and term babies $(12,17)$. BPD is a leading cause of neonatal mortality and morbidity during the first year of life. Lowering

Table 5. Complications*

\begin{tabular}{lcc}
\hline \multicolumn{1}{c}{ Complication } & \multicolumn{2}{c}{ Group } \\
\cline { 2 - 3 } \multicolumn{1}{c}{ Dex $(n=19)$} & Placebo $(n=21)$ \\
\hline Insulin therapy & $8(42 \%)$ & $6(29 \%)$ \\
Pressors & $4(21 \%)$ & $5(24 \%)$ \\
Antihypertensives & $0(0 \%)$ & $0(0 \%)$ \\
IVH (grade I) & $2(11 \%)$ & $3(14 \%)$ \\
IVH (>grade I) & $6(32 \%)$ & $5(24 \%)$ \\
Days to regain birth weight & $23 \dagger$ & $22 \dagger$ \\
NEC & $0(0 \%)$ & $3(14 \%)$ \\
ROP (any stage) & $10(53 \%)$ & $11(52 \%)$ \\
Air leak (PIE or pneumothorax) & $1(5 \%)$ & $4(19 \%)$ \\
Home oxygen & $2(11 \%)$ & $1(5 \%)$ \\
Home medications & $2(11 \%)$ & $4(19 \%)$ \\
Positive admission blood cultures & $1(5 \%)$ & $2(10 \%)$ \\
\hline
\end{tabular}

* Dex, dexamethasone; IVH, intraventricular hemorrhage; NEC, necrotizing enterocolitis; ROP, retinopathy of prematurity; PIE, pulmonary interstitial emphysema.

$\dagger$ Median. 

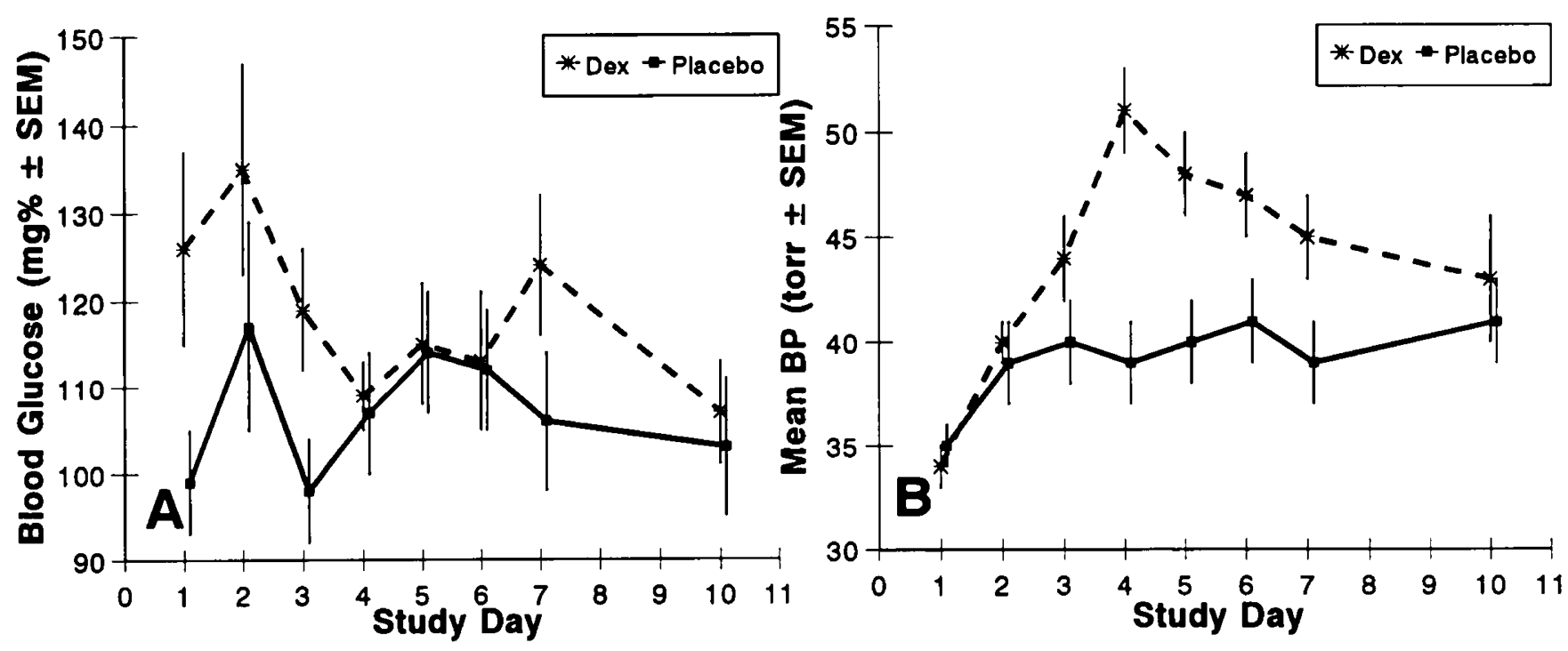

Figure 3. Changes in mean blood glucose $(A)$ and mean blood pressure $(B)$ during the first $10 \mathrm{~d}$ of age (mean \pm SEM) by study group.

the incidence and severity of BPD would offer significant benefit to this high-risk group of babies. By decreasing the need for assisted ventilation and supplemental oxygen in the early stages of the disease process and alleviating the need for further pharmacologic interventions, the potential for adverse sequelae would be substantially reduced.

The exact pathogenesis of BPD remains unclear. One hypothesis for the development of BPD is that hyperoxic injury and barotrauma from mechanical ventilation cause lung cell membrane damage and the release of potent inflammatory mediators (18). This inflammatory response, with an influx of neutrophils, generates oxygen radicals and the release of proteolytic enzymes. This process evolves into chronic lung disease, with varying degrees of fibrosis, because of a cascade of events including cytokine release and enzymatic damage (18). The premature infant is at greater potential risk for hyperoxiainduced injury because of a relatively deficient pulmonary antioxidant enzyme system $(19,20)$. Similar to the surfactant system, the pulmonary antioxidant enzyme system matures rapidly late in gestation and may represent a necessary preparatory event for the transition to a relatively hyperoxic environment after birth $(20,21)$.

Animal studies have demonstrated that the pattern of pulmonary antioxidant enzyme maturation can be accelerated by the administration of steroids $(22,23)$. Additionally, the administration of dexamethasone in term neonatal piglets decreased the extent of lung injury caused by hyperoxia and mechanical ventilation as determined both histologically and by analysis of bronchoalveolar lavage $(24,25)$. The early administration of dexamethasone may reduce the early inflammatory response that normally occurs in the pathogenesis of BPD.

For this initial study, we chose the population at highest risk for development of BPD (6). The role of prophylactic dexamethasone intervention in this population, in an era of exogenous surfactant replacement therapy, has not been previously studied. Yeh et al. (13) demonstrated improved tidal volume, minute ventilation, and lower MAP requirement during the first week of life in babies with non-surfactant-treated RDS who received early dexamethasone, tapered over the first $12 \mathrm{~d}$ of age. We demonstrated similar short-term results (i.e. lower MAP and $\mathrm{FiO}_{2}$, improved tidal volume) with only two doses of dexamethasone in a surfactant-treated population of babies with RDS who were of an earlier gestational age (26-27 wk versus $30 \mathrm{wk}$ in the Yeh study). Differences in tracheal aspirate elastase and $\alpha_{1}$-proteinase inhibitor activities as well as other markers of inflammation (i.e. cell count, differential) have been demonstrated in the first week of age between babies with RDS who develop BPD and those who do not (26). Early dexamethasone may function by interrupting the cytokine cascade that generates this early inflammatory response in those babies who ultimately develop BPD. Tumor necrosis factor- $\alpha$ is a potent mediator of pulmonary inflammation and was shown to increase after $\mathrm{d} 3$ of age in premature babies with RDS (27). Levels of tumor necrosis factor- $\alpha$ were higher in the group requiring prolonged oxygen treatment beyond $28 \mathrm{~d}$ of age and were reduced in six babies by dexamethasone treatment (27). In vitro studies have shown that the expression of IL-8, a potent neutrophilactivating and chemotactic peptide produced by mononuclear phagocytes, was inhibited by pretreatment with dexamethasone in stimulated alveolar macrophages (28). The treatment with dexamethasone after stimulation, however, failed to inhibit IL-8 expression (28). This suggests that a temporal limitation may exist beyond which the alveolar macrophage is not affected by dexamethasone administration.

If early dexamethasone interrupts the cascade of events that results in an inflammatory response and ultimately BPD in babies with RDS, one would predict that such an intervention would affect both survival and the incidence of BPD. Yeh et al. (13) demonstrated a decrease in the 
incidence of lung injury with dexamethasone intervention (39\% versus $65 \%$ for the placebo group). In our study, both survival and survival without BPD were greater in the dexamethasone group, approaching but not reaching statistical significance. This benefit was greater than we had anticipated and will be useful in planning future trials, which are clearly indicated.

No significant complications were noted, with the exception of an elevation of mean blood pressure in the group receiving dexamethasone. This blood pressure elevation returned to control group levels by study $\mathrm{d} 10$ and did not require pharmacologic intervention. Limiting the duration of dexamethasone administration therefore did not eliminate the previously reported elevation of blood pressure $(9,11,13)$. Blood glucose value differences were not clinically significant, although $42 \%$ in the dexamethasone group received insulin therapy versus $29 \%$ in the placebo group. Although the difference in the need for insulin was not statistically significant, it may well prove to be significant with a larger sample size. The magnitude of difference, however, may be quite acceptable in light of the potential benefits to be gained. In contrast to the results of the study of Yeh et al. (13), no delay in the time to regain birth weight was demonstrated. The continued potential for side effects, despite a very limited dexamethasone dosing regimen, argues for the need to determine the proper timing and minimal duration of dosing to achieve efficacy while maximizing safety.

Both the timing and duration of dexamethasone administration as well as the population studied differed substantially from previously published work. For this phase I study, we chose a priori a total number of subjects that was adequate to provide an indication of the magnitude of both beneficial and harmful effects and that could be used to determine a formal sample size for a planned multicenter trial. To detect a significant difference in surfactant-treated RDS babies of $<30$ wk gestation with respect to "alive and free of BPD" (significance level 5\%, power 80\%), 56 patients in each treatment group need to be enrolled.

The results of this phase I study to test the efficacy and safety of two early doses of dexamethasone suggest that such administration in a defined, high-risk population improves short-term pulmonary function and may have long-term benefits including improved survival. The lack of large increases in adverse effects is encouraging. These results justify a larger, multicenter, randomized trial to further assess clinical efficacy and safety.

Acknowledgments. The authors thank Linda Reubens, R.N., and Kathy Brown, R.N., for data collection and monitoring; Robert Notter, M.D., Ph.D., for his helpful suggestions; and Donald L. Shapiro, M.D., whose interest and support before his death facilitated the development of this project.

\section{REFERENCES}

1. Kraybill EN, Runyan DK, Bose CL, Khan JH 1989 Risk factors for chronic lung disease in infants with birth weights of 751-1000 grams. J Pediatr 115:115-120

2. Watson ED, Henderson-Smart DJ, Storey GNB, Peat B, Grattan-Smith P 1987 Perinatal factors and the development of chronic lung disease in preterm infants: a case control study. Aust Paediatr J 23:181-184

3. Smith JA, Tabachnik E, Duncan WJ, Reilly BJ, Levison H 1981 Pulmonary function and bronchial hyperactivity in long-term survivors of bronchopulmonary dysplasia. Pediatrics 68:336-340

4. Kendig JW, Notter RH, Cox C, Aschner JL, Benn S, Bernstein RM, Hendricks-Munoz K, Maniscalco WM, Metlay LA, Phelps DL, Sinkin RA, Wood BP, Shapiro DL 1988 Surfactant replacement therapy at birth: final analysis of a clinical trial and comparisons with similar trials. Pediatrics 82:756-762

5. Pediatric Research Disorders, Division of Lung Diseases 1986 NHLB, NIH, NIH Publication No. 86-2107, Bethesda, MD

6. Sinkin RA, Cox C, Phelps DL 1990 Predicting risk for bronchopulmonary dysplasia: selection criteria for clinical trials. Pediatrics 86:728-736

7. Mammel MC, Green TP, Johnson DE, Thompson TR 1983 Controlled trial of dexamethasone therapy in infants with bronchopulmonary dysplasia. Lancet 1:1356-1358

8. Bourchier D 1988 Dexamethasone therapy in severe bronchopulmonary dysplasia. Aust Paediatr J 24:41-44

9. Avery GB, Fletcher AB, Kaplan M, Brudno DS 1985 Controlled trial of dexamethasone in respirator-dependent infants with bronchopulmonary dysplasia. Pediatrics 75:106-111

10. Kramer Ll, Hultzen C 1978 The role of steroids in early bronchopulmonary dysplasia. Pediatr Res 12:564A(abstr)

11. Cummings JJ, D'Eugenio DB, Gross SJ 1989 A controlled trial of dexamethasone in preterm infants at high risk for bronchopulmonary dysplasia. N Engl J Med 320:1505-1510

12. Sinkin RA, Phelps DL 1987 New strategies for the prevention of bronchopulmonary dysplasia. In: Stern L (ed) Clinics in Perinatology. WB Saunders, Philadelphia, pp 599-620

13. Yeh TF, Torre AR, Anyebuno MA, Pildes RS 1990 Early postnatal dexamethasone therapy in premature infants with severe respiratory distress syndrome: a double-blind, controlled study. J Pediatr 117:273-282

14. Kendig JW, Notter RH, Cox C, Reubens LJ, Davis JM, Maniscalco WM, Sinkin RA, Bartoletti A, Dweck HS, Horgan MJ, Risemberg H, Phelps DL, Shapiro DL 1991 A comparison of surfactant as immediate prophylaxis and as rescue therapy in newborns less than 30 weeks gestation. N Engl J Med 324:865-871

15. Davis JM, Veness-Meehan K, Notter RH, Bhutani VK, Kendig JW, Shapiro DL 1988 Changes in pulmonary mechanics after administration of surfactant to infants with respiratory distress syndrome. N Engl J Med 319:476-479

16. Shennan AT, Dunn MS, Ohlsson A, Lennox K, Hoskins EM 1988 Abnormal pulmonary outcomes in premature infants: prediction from oxygen requirements in the neonatal period. Pediatrics 82:527-532

17. Bancalari E, Sosenko I 1990 Pathogenesis and prevention of neonatal chronic lung disease. Pediatr Pulmonol 8:109-116

18. Stenmark KR, Eyzaguirre M, Westcott JY, Henson PM, Murphy RC 1987 Potential role of eicosanoids and PAF in the pathophysiology of bronchopulmonary dysplasia. Am Rev Respir Dis 136:770-772

19. Autor AP, Frank L, Roberts RJ 1976 Developmental characteristics of pulmonary superoxide dismutase: relationship to idiopathic respiratory distress syndrome. Pediatr Res 10:154-158

20. Frank L, Groseclose EE 1984 Preparation for birth into $\mathrm{O}_{2}$-rich environment: the antioxidant enzymes in the developing rabbit lung. Pediatr Res 18:240-244

21. Asayama K, Hayashibe H, Dobashi K 1991 Immunohistochemical study on perinatal development of rat superoxide dismutase in lungs and kidneys. Pediatr Res 29:487-491

22. Frank L, Lewis P, Sosenko IRS 1985 Dexamethasone stimulation of fetal rat lung antioxidant enzyme activity in parallel with surfactant stimulation. Pediatrics 75:569-574

23. Randhawa P, Hass M, Frank L, Massaro D 1986 Dexamethasone increases superoxide dismutase activity in serum-free rat fetal lung organ cultures. Pediatr Res 20:895-898

24. Davis JM, Penney DP, Notter RH, Metlay L, Dickerson B, Shapiro DL 1989 Lung injury in the neonatal piglet caused by hyperoxia and hyperventilation. J Appl Physiol 67:1007-1012

25. Davis JM, Penney DP, Becker J, Shapiro DL 1990 Lung injury in neonatal piglets from hyperoxia and hyperventilation: effects of prophylactic dexamethasone. Pediatr Res 27:299A(abstr)

26. Merritt TA, Cochrane CG, Holcomb K, Bohl B, Hallman M, Strayer D, Edwards III DK, Gluck L 1983 Elastase and alpha-1-proteinase inhibitor activity in tracheal aspirates during respiratory distress syndrome. J Clin Invest 72:656-666

27. Murch SH, MacDonald TT, Wood CB, Costeloe KL 1992 Tumour necrosis factor in the bronchoalveolar secretions of infants with the respiratory distress syndrome and the effect of dexamethasone treatment. Thorax 47:44-47

28. Standiford TJ, Kunkel SL, Rolfe MW, Evanoff HL, Allen RM, Strieter RM 1992 Regulation of human alveolar macrophage- and blood monocyte-derived interleukin-8 by prostaglandin $\mathrm{E}_{2}$ and dexamethasone. Am J Respir Cell Mol
Biol 6:75-81 